\title{
CATEGORIAS DE NARRATIVAS: PRINCIPAIS USOS EM PESQUISAS E FORMAÇÃO DE PEDAGOGAS
}

\author{
CATEGORIES OF NARRATIVES: \\ MAIN USES IN RESEARCH AND TRAINING OF PEDAGOGUES
}

\author{
CATEGORÍAS DE NARRATIVAS: \\ PRINCIPALES USOS EN INVESTIGACIONES Y FORMACIÓN DE PEDAGOGAS
}

\author{
Carla Barbisan ${ }^{1}$, Maria Auxiliadora Bueno Andrade Megid $^{2}$
}

\begin{abstract}
RESUMO
Apresentamos neste artigo resultados parciais de uma pesquisa, do tipo análise documental, que versa sobre narrativas no âmbito da formação de pedagogas e das pesquisas nesta mesma área, que considerou 16 obras produzidas entre os anos de 2006 e 2014, sendo 12 dissertações e quatro teses, todas disponíveis da Biblioteca Digital Brasileira de Teses e Dissertações. No decurso de pesquisa, a partir das leituras de base e das pesquisas consideradas para análise, surgiram constatações que surgiram sobre o tema, mas também que nos levaram à necessidade de elaboração de uma categorização das narrativas como meio de melhor visualizarmos seus distintos usos. Em paralelo, no intuito de ampliar a visão sobre o tema, também concebemos um levantamento parcial das nomenclaturas utilizadas ao seu tratamento. Tais elaborações possibilitaram-nos uma visão mais ordenada das narrativas e seus usos, o que contribuiu com o andamento da pesquisa. Inferimos que a organização aqui apresentada pode direcionar o olhar de pesquisadores, professores e estudantes, promovendo a compreensão de uma diversidade no emprego das narrativas, indicando possibilidades mais adequadas de sua utilização. Entendemos que estes resultados possam contribuir com as pesquisas e práticas pedagógicas que se utilizam dessa ancoragem metodológica.
\end{abstract}

PALAVRAS-CHAVE: Narrativas; Formação de pedagogas; Pesquisas narrativas.

\section{ABSTRACT}

This article presents the partial results of a research, of documental analysis nature, about narratives for pedagogical education and other pieces of research in this area, and it has considered 16 essays written from 2006 to 2014, of which there were 12 dissertations and 4 theses, available at the Brazilian Digital Library of Theses and Dissertations. In the course of this research and based on the reading of the papers considered for analysis, some questionings and substantiations about the topic have come up and led us to categorizing the narratives as a way to better visualize their different uses. In parallel, in order to broaden the view over the topic, we have also made a partial survey of the terminology used to refer to it. It has enabled us to have a more organized view of the narratives and their uses, which has contributed to the development of the research. We have inferred that the organization presented herein may direct the view of researchers, teachers and students by promoting the understanding of the varied use of narratives and indicating more

\footnotetext{
${ }^{1}$ Mestre em Educação - Pontifícia Universidade Católica de Campinas (PUC-CAMPINAS) - Campinas, SP - Brasil. E-mail: c.barbisan@uol.com.br

2 Doutora em Educação - Universidade Estadual de Campinas - Campinas, SP - Brasil. Professora titular Pontifícia Universidade Católica de Campinas (PUC-CAMPINAS) - Campinas, SP - Brasil. E-mail: $\underline{\text { dmegid@puc- }}$ campinas.edu.br
}

Submetido em: 24/07/2017 - Aceito em: 12/03/2018

(C) ETD-Educação Temática Digital Campinas, SP $\quad$ v.20 $\quad$ n.4 $\quad$ p.979-996 out./dez. 2018


suitable possibilities to use them. We understand that these results may contribute with the research and the pedagogical practices that use this methodological anchorage.

KEYWORDS: Narratives; Pedagogical Education; Narrative research.

\section{RESUMEN}

En este artículo se presentan los resultados parciales de una investigación, del tipo análisis documental, que versa sobre narrativas en el ámbito de la formación de Pedagogas y de las investigaciones en esta misma área. Para su elaboración se han considerado 16 obras producidas entre los años 2006 y 2014, siendo 12 disertaciones y cuatro tesis, todas disponibles en la Biblioteca Digital Brasileña de Tesis y Disertaciones. En el curso de investigación, a partir de las lecturas de base y de las investigaciones consideradas para análisis, surgieron constataciones sobre el tema, pero también varias interrogantes, que nos llevaron a la necesidad de elaboración de una categorización de las narrativas como medio de mejor visualizar sus distintos usos. En paralelo, con la intención de una visión amplia sobre el tema, también concebimos un levantamiento parcial de las nomenclaturas utilizadas para su tratamiento. Tales elaboraciones nos posibilitaron una visión más ordenada de las narrativas y sus usos, que, a su vez, facilitó el progreso de la investigación. Inferimos que la organización aquí presentada podrá orientar la forma de ver de investigadores, profesores y estudiantes, promoviendo así la comprensión de una diversidad en el empleo de las narrativas, lo que indica posibilidades más adecuadas em su utilización. Entendemos que estos resultados puedan contribuir con las investigaciones y prácticas pedagógicas que se utilizan de ese anclaje metodológico.

PALABRAS CLAVE: Narrativas; Formación de pedagogas; Investigaciones narrativas.

\section{INTRODUÇÃO}

As narrativas têm sido utilizadas largamente em pesquisas na área da educação e também como prática pedagógica em cursos de formação de professores. Por isso mesmo vêm sendo exploradas por autores que nos mostram seus usos e especificidades, principalmente no que tange ao valor que elas conferem à experiência e subjetividade envolvidas na formação de professores e em pesquisas. No entanto, ainda há muito que se investigar e dissertar sobre narrativas.

Durante nossa pesquisa bibliográfica sobre este tema no âmbito das pesquisas em Pedagogia e também no de formação de pedagogas, observamos que ainda há falta de literatura que aborde aspectos mais específicos sobre as narrativas, que as categorize ou epistemologicamente as explique. Sendo assim, neste artigo, apresentamos uma divisão das narrativas, que são categorias criadas por estas pesquisadoras durante o processo investigativo, que ajudaram a visualizar seus usos, facilitando o pesquisar. $O$ que aqui expomos, no entanto, não são os resultados da referida pesquisa, mas a descoberta feita durante o processo de investigação que facilitou a mesma.

Os autores aqui citados embasam nossa pesquisa e proposta de categorização das narrativas por apresentarem menção em suas obras a nomenclaturas utilizadas nas narrativas e por utilizarem as narrativas em suas próprias pesquisas, entendendo-as como

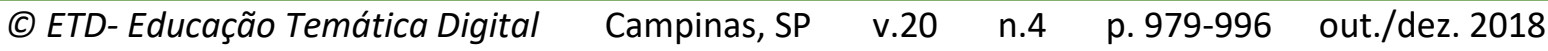


uma possibilidade inesgotável de investigação, expondo os resultados observados com elas. Ressaltamos Clandinin e Connelly por darem um valor supremo às pesquisas narrativas, dimensionando-as ao patamar de uma espécie de filosofia em pesquisa, que implica em uma série de cuidados e um complexo relacionamento com vários itens que compõem a ação da pesquisa narrativa. Os referidos autores são percursores em narrativas e apresentam em suas obras fundamentos de outros autores exponenciais ao pensamento narrativo, como Larrosa $(2002,2011)$ e Dewey (1976). Por fim, destacamos estes autores/pesquisadores por demonstram em suas obras o respeito incondicional às narrativas. Suas obras elucidaram muitas dúvidas e encantaram por sua integridade ética à ação de pesquisa, que consideramos fundamental.

Vale ressaltar que as quatro categorias aqui apresentadas ainda podem ser melhor apuradas se divididas individualmente em subcategorias, o que revelaria vertentes mais acuradas das narrativas. No entanto, por ora, nosso objetivo se atém à apresentação mais generalizada das narrativas, que se dá por meio de quatro grandes categorias por nós elaboradas.

O artigo, por primeiro, trará um panorama sobre as narrativas no que tange ao seu surgimento, aos usos e contribuições às pesquisas e também à formação de professores, indicando algumas especificidades das narrativas, que são mais exploradas pela literatura disponível nesta área. Apresentamos ainda uma relação de nomenclaturas dadas às narrativas, formas de tratamento encontradas em livros, teses e dissertações por nós investigadas

Os itens posteriores trarão as narrativas separadas em quatro categorias, que são: Pesquisa Narrativa; Pesquisas que se Utilizam de Narrativas; Narrativas como Prática de Formação; e Escrita Narrativa. Em alinhamento a autores que tratam de narrativas, apresentaremos nossa visão de tais categorias e nosso entendimento sobre suas principais características.

\section{PROCESSO METODOLÓGICO}

Este artigo é resultado do processo de pesquisa que se centrou na análise de 16 obras, sendo quatro teses e doze dissertações, publicadas entre os anos de 2006 e 2014, que utilizam as narrativas na formação de pedagogas. Tais obras analisadas foram selecionadas a partir de busca sistematizada na Biblioteca Digital Brasileira de Teses e Dissertações (BDTD). Com ela buscou-se identificar os diferentes usos de narrativas em cursos de Pedagogia, procurando também mapear seus aspectos recorrentes, com a finalidade de apresentar um panorama metodológico sobre como as narrativas têm servido

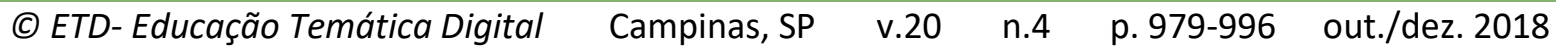


à formação de pedagogas e às pesquisas sobre essa área. Os objetivos específicos foram apresentar teses e dissertações que utilizassem narrativas; identificar e analisar os temas tratados nas pesquisas que as utilizam, identificando as pesquisas que utilizaram na própria escrita da tese e dissertação, um recurso narrativo e, identificar e analisar o uso de narrativas na formação de pedagogas como recurso para sua formação; em práticas docentes e no desenvolvimento da formadora que as utiliza como recurso, além da produção de demais dados que pudessem ser consolidados no processo investigativo.

Cabe esclarecer que o presente artigo, insere-se, portanto na dinâmica dessa pesquisa de caráter mais global sobre a formação de pedagogas, sendo, entretanto, um recorte que se constrói sobre ela, na qual buscamos refletir e sistematizar as lacunas relacionadas às referências bibliográficas sobre as pesquisas narrativas neste contexto. 0 objetivo do artigo é propiciar a categorização dos variados tipos de narrativas com as quais nos deparamos ao longo do processo de inquirição das fontes.

Para proceder à categorização das narrativas e à elaboração de um quadro para apresentar os diferentes termos encontrados na literatura sobre elas, partimos da leitura de Clandinin e Connelly (2011), que nos deu uma visão mais profunda e ampla sobre Pesquisa Narrativa, seguindo com a leitura de autores como Souza (2008, 2013), Prado (2005), Passegui $(2013,2016,2017)$ entre outros, que nos deram embasamento teórico para categorizar melhor outros usos das narrativas.

No prosseguir, nos dedicamos a registrar os diferentes tipos de termos utilizados pelos variados autores, criando um quadro, onde termos repetidos foram excluídos e os inéditos acrescidos. Após a criação deste quadro, coube-nos escolher os principais usos das narrativas, o que derivou na organização de quatro categorias que descrevemos neste artigo.

\section{AS NARRATIVAS}

Existem estudos que apontam o século $\mathrm{V}$ antes de Cristo como o início das histórias de vida e escritos sobre si, embora seja possível afirmar que o falar e o conversar sobre si já existiam muito antes (SOUZA; OLIVEIRA, 2013). Portanto, ao falarmos de narrativas não estamos discorrendo sobre algo novo, mas de um modo de expressão de si que ocupou seu espaço no campo das pesquisas, principalmente sociais, e nas práticas pedagógicas, uma vez que sua utilização vem ganhando força com o passar do tempo.

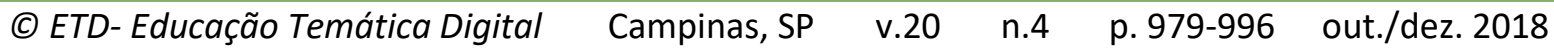


Segundo Alves-Mazzotti e Gewandsznajder (2002), a busca por um tipo de ciência que primasse por transformações sociais teve seu auge na década de 1960. Naquela época, cresceu o questionamento aos pensamentos dominantes das ciências, o que possibilitou, aos poucos, maior liberdade aos 'paradigmas qualitativos', nos quais as narrativas se encaixam por primar pela valorização das experiências, como afirmam Clandinin e Connelly (2011, p. 24): “Assim, as ciências sociais são fundadas com o foco no estudo da experiência. Experiência é, portanto, o ponto inicial e o termo chave para todas as pesquisas em Ciência Social". Em um contexto de mudanças paradigmais e conquista de espaços à pesquisa qualitativa, as narrativas vêm se estabelecendo e ganhando respeito como modalidade de pesquisa, como prática pedagógica e como gênero de escrita em pesquisas.

As narrativas surgiram como um meio de dar 'voz' às minorias, permitindo que essas vozes fossem efetivamente ouvidas, a grupos excluídos ou relegados, e foi sob esta ótica que se deu a propulsão do 'contar sobre si e sua formação' na área educacional. Viu-se no uso das narrativas a possibilidade da fundamental socialização e divulgação das experiências docentes. Este movimento teve início no começo dos anos 1980, quando, por meio de relatórios americanos sobre educação, apresentou-se a péssima situação educacional do país, o que gerou uma mudança de foco nas pesquisas desta área, que passou a ser os saberes docentes e a profissionalização (VARANI; FERREIRA; PRADO, 2007).

As características qualitativas das narrativas se adequam às pesquisas da área social que tratam de modo acurado as subjetividades inerentes às suas produções científicas. Da mesma forma, por sua subjetividade e riqueza de resultados, contribuem à aprendizagem, sendo muito utilizadas na área de formação de professores. Portanto, o uso de narrativas no universo da educação - seja em pesquisa ou em formação -, propicia à subjetividade um espaço que lhe foi relegado por séculos no mundo acadêmico: sua importância científica.

Neste artigo desenvolvemos o pensar específico sobre narrativas verbais no âmbito autobiográfico, ou seja, as orais e escritas, mas, no entanto, sem deixar de destacar que há outros modos para se narrar. A forma verbal de narração acaba sendo a mais utilizada, mas há outras que devem ser consideradas, como: audiovisuais, fotográficas, musicais, dramática, plásticas e tantas outras que buscam contar histórias que trazem em si experiências que se opta por compartilhar.

Desde o início de nossa pesquisa percebemos a grande diversidade quanto à nomenclatura utilizada ao referir-se às narrativas. De forma geral, são formas correlatas, pois enfocam essencialmente os modos de trazer ao presente as experiências que são escolhidas para serem reveladas aos outros. Para nomear os gêneros textuais utilizados para contar sobre as ocorrências da vida das pessoas, sejam histórias de formação, pessoais ou

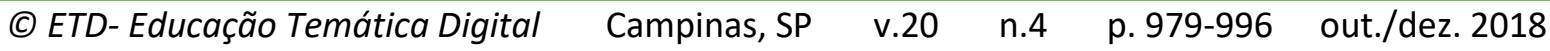


profissionais, encontramos termos como: "[...] diários, cartas, memórias, portfólio, novela de formação, memorial de formação..." (PRADO; SOLIGO, 2005, p. 49). Ainda, narrativa, autobiografias, biografia; narrativas de formação (FREITAS; GHEDIN, 2015); “[...] relatos de vida, memória, história oral, abordagem biográfica, método biográfico, etnobiografia [...]" (CHIZZOT, 2011, p. 101); memórias de formação (BRITO, 2007); e outros termos identificados em teses e dissertações por nós analisadas. Para melhor identificação e compreensão ao leitor sobre a variedade de termos para nomeação de narrativas orais ou escritas ou de métodos de pesquisa narrativa, organizamos e quantificamos termos identificados em ordem alfabética:

\section{Quadro 1 - Termos usados para se referir a narrativas ou a seus usos}

\begin{tabular}{|l|l|l|}
\hline 1. Abordagem biográfica & 11. Entrevista narrativa & 21. Narrativa \\
2. Autobiografias & 12. Etnobiografia & 22. Narrativas autobiográficas \\
3. Biografia & 13. História de vida & 23. Narrativas autobiográficas de formação acadêmica \\
4. Cartas & 14. História oral & 24. Narrativas de formação \\
5. Conversas & 15. História oral temática & 25. Narrativa histórica \\
6. Constelação narrativa tradicional & 16. Instantâneos de formação & 26. Narrativas orais \\
7. Constelação narrativa exemplar & 17. Memórias & 27. Narrativas reflexivas \\
8. Constelação narrativa crítica & 18. Memorial de formação & 28. Novela de formação \\
9. Constelação narrativa genérica & 19. Memórias de formação & 29. Porttólio \\
10. Diários & 20. Método biográfico & 30. Relatos de vida \\
\hline
\end{tabular}

Fonte: Elaboração das autoras.

O quadro, no entanto, não apresenta a totalidade dos termos, haja vista que nossa investigação sobre o tema das narrativas, não teve por objetivo esgotar essas possibilidades. Mas, ainda que em levantamento parcial sobre a nomenclatura dada aos modos de operar com narrativas, é possível verificar como o contar sobre si é diversificadamente referenciado. A opção pelo uso de determinada nomenclatura ocorre em conformidade aos autores com os quais se trabalha e com o enfoque de uso.

Pensamos ser necessário ao entendimento amplo das narrativas que se faça um estudo específico e detalhado, que esmiúce a epistemologia e o uso de cada termo, onde se apresente um panorama de como cada nomenclatura tem sido explorada por pesquisadores e formadores e, até, esclarecendo sobre o uso adequado à cada um dos termos, o que não é, no entanto, o objetivo deste escrito.

Seja qual for a nomenclatura dada às narrativas, um fato comum a todas é a condição sine qua non da exposição de experiências. Aqui tratamos experiência pela ótica de Larrosa (2002) que a defende como configurar-se em um processo absolutamente pessoal e passional, que não ocorre da mesma forma em duas pessoas. A relação direta

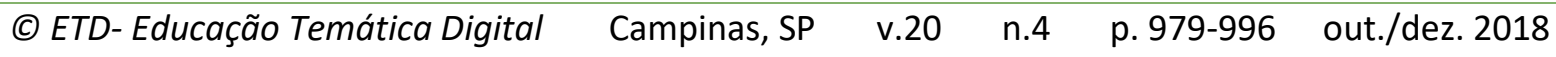


entre experiência e narrativas é um dos pontos mais discursados por autores. Encontramos a explicitação desta relação em autores como: Clandinin e Connelly (2011); Varani, Ferreira e Prado (2007); Cunha (1997), entre outros. Cabe destacar que há autores como Larrosa (2002, 2011) e Dewey (1976), que mesmo sem se referir diretamente às narrativas apresentam em seus textos a importância das experiências à aprendizagem.

O sentido das narrativas se dá pela emissão e recepção de uma história, que por sua vez, traz outras histórias, imbuídas de experiências de quem as conta. Ou seja, as narrativas pressupõem um emissor e um interlocutor. Este momento onde, aparentemente, o narrador e interlocutor ocupam papéis opostos - de expressão e apreensão de alguma história -, pode gerar para ambos o ressignificar de diversos pensamentos, sentimentos, saberes e experiências. O relatado pode gerar a comunhão entre os sujeitos, momento em que o ouvinte passa, de alguma forma, a fazer parte da história contada, como uma espécie de cúmplice.

É preciso que o interlocutor tenha interesse pelo que é narrado, só assim pode ocorrer uma das grandes qualidades das narrativas que é sua capacidade de transformação dos sujeitos, já que "[...] as histórias que lemos e ouvimos nos remetem sempre às nossas próprias histórias e às nossas experiências pessoais" (PRADO; SOLIGO, 2005, p. 53), trazendo reflexões que implicam algum tipo de alteração pessoal.

Ao iniciar nossa exploração pelo mundo das narrativas, tivemos muitas dúvidas e nos deparamos com a necessidade de conceitos epistemológicos que clareassem nossa visão sobre o que é uma narrativa, e buscamos literaturas que nos dessem explicações mais específicas sobre seus usos. Mas as respostas a certas dúvidas sobre elas ainda estão em aberto, haja vista o recente alargamento do uso de suas possiblidades. Ainda não há respostas contundentes, como, por exemplo, uma definição concreta sobre o que de fato é uma boa narrativa, pois este tipo de pesquisa ainda se encontra em desenvolvimento (CLANDININ; CONNELLY, 2011). Mas, mesmo envoltas por incertezas, as pesquisas que utilizam narrativas têm sido exploradas na área da educação, por serem: metodologicamente qualitativas - o que se articula com princípios das ciências sociais; por permitir a escuta atenta da voz de sujeitos e classes de profissionais; por serem interativas; e por se enquadrarem no momento social atual, que é de maior liberdade, interesse e respeito por experiências alheias.

Não há, portanto, certezas epistemológicas. O que nossa pesquisa revelou nos fez compreender que o termo 'narrativas' está a serviço de fins correlatos, mas que possuem especificidades, que quando não são esclarecidas geram confusões. Sentimos a necessidade de separar as narrativas por categorias que acreditamos facilitar a visualização e

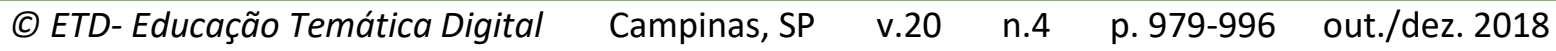


compreensão de suas possibilidades. Após criarmos esta categorização, encontramos em Vicentini, Souza e Passegui (2013) um texto com uma categorização das narrativas, inspirada em Bolívar (2001), um tipo de caracterização que divide as narrativas em três grupos:

[...] as narrativas (auto)biográficas sob o aporte teórico metodológico das Histórias de Vida ou da Investigação-formação as entendo, com inspiração em Bolívar, em seu tríplice aspecto: como fenômeno (a narrativa oral ou escrita per se; ato artesanal de narrar-se intencional e reflexivamente que ocorre no encontro narrador/pesquisador; narrador/formador); como metodologia de investigação (a narrativa como fonte (auto) biográfica privilegiada, compreendida desde o ato narrativo processualmente entrelaçado com outras fontes, para a construção metodológica da História de Vida, da qual participam narrador e pesquisador) e, ainda, como processo formativo de ressignificação do vivido (narrativa como reflexão (auto)biográfica do narrador - de si e de sua profissionalidade - como dispositivo de autoconhecimento; de construção identitária como movimento no contexto do vivido, oportunizados pelo processo narrativo, que pode ter o memorial de formação como produtor de sentido e como produção, construído na interação aprendente de dois sujeitos históricos - narrador e aquele que com ele faz a mediação (auto)biográfica, o formador. (VICENTINI; SOUZA; PASSEGUI, 2013, p. 9, grifos dos autores).

Há semelhanças entre ambas as categorizações, as que criamos e as que acabamos de apresentar, mas há distinções importantes como o número de categorias, três as desses autores e quatro as nossas e quanto ao enfoque dado a cada uma. Sendo assim, apresentamos a seguir as categorias por nós elaboradas, que acreditamos somar às elucidações necessárias às narrativas: 1 - Pesquisa Narrativa; 2 - Pesquisas que se Utilizam de Narrativas; 3 - Narrativas como prática de Formação ou de desenvolvimento; e 4 Escrita Narrativa.

\section{PESQUISA NARRATIVA}

A Pesquisa Narrativa é um modo de pesquisa defendido por Clandinin e Connelly (2011), onde há características mais profundas de relação com tudo que envolve a pesquisa e a produção das narrativas. A Pesquisa Narrativa não é somente um modo de pesquisar, mas um modo de se pensar pesquisa e de se estar pesquisador, como definem os autores: "Este aprendizado de 'pensar narrativamente' nas fronteiras entre narrativas e outras formas de pesquisa é, talvez, a única e mais importante característica do pensamento narrativo bem sucedido" (CLANDININ; CONNELLY, 2011, p. 57, grifo nosso).

Pesquisar Narrativamente requer profundo envolvimento no que tange: à temporalidade, pois se entende que os ocorridos possuem passado, presente e futuro, que devem ser considerados; ao contexto, pois todos os elementos que fazem parte da pesquisa devem ser observados, sendo que, no entanto, "[...] a pessoa em contexto é o que interessa" (CLANDININ; CONNELLY, 2011, p. 66); à duração do trabalho em campo, que deve ser maior, para que todas as dimensões possam ser realmente contempladas; à atenção

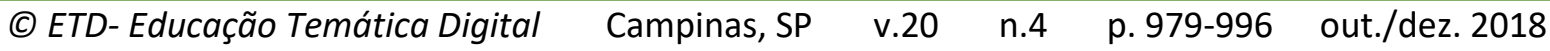


defendem o respeito ao participante, que deve fazer parte deste processo, podendo conhecer o texto final redigido para aprová-lo ou não. Esta inclusão do participante instaura o respeito e fidedignidade ao que é exposto e traz a valorização da autoria do que é produzido, ambos essenciais a este modo de pesquisa.

Estes são alguns dos pontos considerados por nós como sendo os mais importantes sobre pesquisar narrativamente, embora existam outros tantos que merecem também entendimento em algumas investigações. Falaremos agora sobre pesquisas que se utilizam de narrativas.

\title{
5 PESQUISAS QUE SE UTILIZAM DE NARRATIVAS
}

Este tipo de pesquisa não possui, necessariamente, os mesmos níveis de rigor das Pesquisas Narrativas, pois somente utilizam as narrativas como forma de construção de dados, sem incorporar ao seu tratamento o que Clandinin e Connelly (2011) tratam por "o pensar narrativo" que encerra uma série de pressupostos éticos e de envolvimento com todos os componentes da inquirição, principalmente com os participantes.

O uso de narrativas voltadas a pesquisas, neste caso as de formação de professores, é um meio de se chegar à dimensão das experiências que de fato se fizeram importantes, como marcas na formação profissional de cada um.

\begin{abstract}
As narrativas permitem que as pesquisadoras entrem em contato com verdades veladas, com sensações subjetivas, com emoções incompreendidas que aos poucos vão se revelando e contando a história de cada uma, que se une à história de todas, trazendo ao campo da pesquisa em Pedagogia uma riqueza de informações de diversos níveis, que podem contribuir com a melhoria dos cursos que formam o professorado. (BARBISAN; MEGID, 2017, p. 80).
\end{abstract}

As narrativas não são necessariamente a única forma de construção de dados, podendo ser aliadas a outras. É preciso ressaltar que há fragilidades no entendimento do que são narrativas, pois, muitas vezes as pesquisas dizem usar narrativas, mas, de fato, usam entrevista com perguntas fechadas, "[...] onde não há liberdade de expressão, mas um direcionamento para as respostas que impossibilita a reflexão desejada em uma narrativa." (BARBISAN; MEGID, 2017, p. 79-80)

\section{NARRATIVAS COMO PRÁTICA DE FORMAÇÃO}

As narrativas de formação são cada dia mais usadas no processo formativo de professores uma vez que implica na reflexão de determinado tema, ou da própria formação, ou da própria vida, sendo uma prática pedagógica usada de variadas formas no processo de aprendizagem. $\mathrm{O}$ uso de narrativas pode ser uma possibilidade que leve o aluno a assumir um papel ativo, de protagonista de sua própria aprendizagem. O exercício da reflexão, seja sobre sua formação, sobre temas específicos das licenciaturas ou sobre seu futuro como professor, faz com que o aluno possa desempenhar papel fundante em sua aprendizagem,

(C) ETD- Educação Temática Digital Campinas, SP $\quad$ v.20 $\quad$ n.4 $\quad$ p.979-996 out./dez. 2018 
já que as narrativas são meios de aprendizagem que viabilizam o pensar sobre situações significantes para o aluno, ou seja, sobre as experiências, que são, em potencial, situações de aprendizagem.

\begin{abstract}
Essa compreensão de formação do sujeito faz-nos desembocar na perspectiva que recoloca o sujeito no lugar de destaque que lhe pertence, para tornar-se um ator que se autonomiza, tornando assim, o sujeito mais consciente do que o constitui enquanto ser psicossomático, social, político e cultural. É essa consciência que nos permite falar de um sujeito de formação. Ele se torna sujeito no momento em que é capaz de intervir no seu processo de aprendizagem e de formação para favorecer e para o orientar. (JOSSO, 1988, apud FREITAS; GHEDIN, 2015, p. 120).
\end{abstract}

O professor aprendiz, assim como o atuante, deve refletir sobre sua própria formação, e isto é fundamental a qualquer aluno de licenciatura, o que faz com que entre em contato com certos porquês de sua aprendizagem ou desaprendizagem. 0 reconhecimento de sua história de formação leva o futuro professor a desenvolver a sensibilidade para atuação a favor de seus alunos. Geralmente as narrativas contribuem para que o formando, ao tornar-se professor, seja mais consciente e não repita com seus alunos, enganos que foram cometidos em sua formação, podendo fazer uso de aspectos que foram positivos em sua aprendizagem.

O cuidado especial que se deve ter com as narrativas como meio de aprendizagem em formação de professores diz respeito aos limites que podem tornar a narrativa um elemento de terapia individual ou grupal - já que o compartilhamento dos escritos é um dos usuais componentes no uso de narrativas em salas de aula -, o que fugiria ao seu real objetivo. Não se descarta a possibilidade de as narrativas serem também uma forma de terapia ou catarse, sendo que estes podem ser resultados naturais, mas não devem tornarse o objetivo. Para que a tal processo seja evitado é necessário o uso consciente das narrativas, com orientação e acompanhamento de pesquisadores/professores que entendam de fato sobre este meio de pesquisa/aula. O foco deve ser muito mais os resultados da reflexão individual do narrador, do que a rememoração e a catarse possível de ser realizada em cada experiência.

Os resultados da escrita de si, a partir do indicado por vários autores, são inegavelmente positivos para o desenvolvimento pessoal e profissional na formação de professores, pois "[...] a escrita autobiográfica é um exercício poderoso de metarreflexão e, portanto, de tomada de consciência de quem somos nós em diferentes dimensões de nossa existência" (NOGUEIRA et al., 2008, p. 173). As narrativas trazem para alunos e professores a oportunidade de mostrarem seus conhecimentos, criando uma rede de troca de saberes e experiências que demonstra as sinergias e geram identificações que fortalecem a cada um e a todos como profissionais da área da educação: "A escrita de narrativas abre espaços e oportuniza, no nosso caso, às professoras em processo de formação, falar-ouvir e lerescrever sobre suas experiências formadoras, descortinar possibilidades sobre a formação através do vivido." (SOUZA, 2008, p. 95).

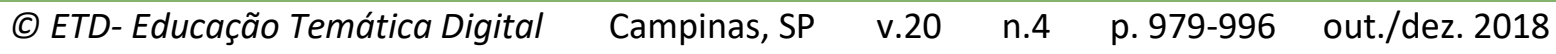


Embora existam outras afirmações relacionadas aos benefícios do uso de narrativas na formação de professores, nos atemos à questão relacionada à necessidade da aceitação, ou seja, da adesão dos alunos à proposta de escrita de si, em processos biográficos.

Para além da dificuldade da escrita, Demartini (2008) também aponta duas questões como entraves no universo das biografias: "Como atribuir sentido e novos significados ao que não se valoriza? [...] Como transformar a própria experiência em conhecimento?" (DEMARTINI, 2008, p. 47). A atribuição de novos significados a uma história é uma das formas de transformação possibilitadas pelo contar das histórias, incluindo as de formação. Um dos fatores que contribuem para isso é o que Tardif (2014), chama de "distanciamento crítico", ou seja, ao evocarmos as memórias, há um afastamento temporal e emocional das mesmas que nos permite uma nova visão sobre os ocorridos. Durante o intervalo de tempo entre o que passou e o relatado em uma escrita narrativa, somam-se outras experiências vividas e saberes desenvolvidos, que, naturalmente, modificam a visão dos fatos, dandoIhes novos significados. Ou seja, a vida transforma os sujeitos, por isso Tardif, citando Heideger, diz que o sujeito não é apenas epistemológico, mas, sim um "sujeito existencial" (HEIDEGER,1972, apud TARDIF, 2014, p. 103). É preciso que se dê valor à história da existência de cada um, pois ela é capaz de revelar informações importantes sobre a sua constituição, que explicam sua personalidade, atitudes, restrições, medos, dificuldades. Mais do que isso, o resgate da história, a reflexão e compreensão para possibilitar os processos de transformação.

Numa pesquisa desenvolvida com professores dos anos inicias em formação, cujo foco era o ensino e a aprendizagem de matemática, Megid $(2009,41)$ afirma que as lembranças das futuras professoras sobre suas memórias escolares, trazidas nas narrativas de formação, evocam as lembranças, "indicando como fomos tecidos ao longo da vida, quantos fios foram usados para que fôssemos constituídos". A autora segue afirmando ser necessário um (re)tecer da "vivência, na perspectiva de construir saberes para a docência" (p. 41).

Entendemos, a partir do exposto, que as narrativas se apresentam como um modo de instigar a reflexão, objeto da formação de professores, e esta reflexão pode contribuir para os sujeitos em formação superarem o segundo obstáculo apontado por Demartini (2008): o de transformar a própria experiência em conhecimento. A reflexão suscita conexões cognitivas que permitem o entendimento de fatos que antes não eram claros. Não é à toa que o tema reflexão é citado em praticamente todos os escritos sobre formação de professores (GARCIA, 1992). Refletir leva o sujeito em formação a descobrir que já possui conhecimentos e competências, "[...] parte importante da competência profissional dos professores tem raízes em sua história de vida" (TARDIF, 2014, p. 69). A identificação dos saberes adquiridos; da trajetória de sua formação; do quanto sua história reflete em sua escolha profissional e em seu modo de compreender a profissão, trazem outra qualidade à formação dos professores, a mais humana. O contar de si por meio de narrativas possibilita o contato com sua "singularidade" e um "mergulho na interioridade" que traz a reflexão sobre sua identidade (SOUZA, 2008).

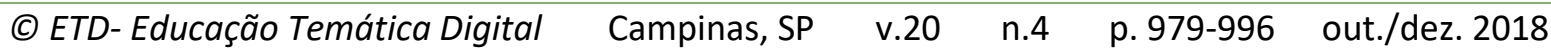


Nas narrativas a aprendizagem de si parte do reconhecimento do que Furlanetto (2009) chamou de "arquivos existenciais", um arsenal de aprendizagens dos quais muitas vezes não é possível dar-se conta sem que haja um estímulo externo que convide a um processo de reflexão profunda. A autora nomeou-os de "Matrizes Pedagógicas", que são representados por diversas situações cotidianas onde tivemos modelos de professores e ou situações de aprendizagem que marcaram, conscientemente ou não, e se tornaram referência de como ser professor. Refletir sobre esses arquivos existenciais e entender os motivos que levaram à profissão docente e de onde vem o modo como atua profissionalmente em sala de aula, como resolve conflitos ou problemas de aprendizagem, entre outras descobertas que o contar sobre a própria formação possibilitam, faz com que seja criada consciência, que, por sua vez, leva às transformações e até à construção de uma identidade. "Assim, narrar nossas histórias é, portanto, um modo de dar a nós mesmos uma identidade" (NOGUEIRA et al, 2008, p. 172).

Em cada narrativa há revelações, histórias muito pessoais que interessam à compreensão dos meandros da formação de professores, como: suas histórias de vida; suas aprendizagens significativas; o relato de formadores que os marcaram; os porquês desta marcas; a origem de possíveis bloqueios; os motivos da escolha da profissão docente; as interferências familiares, suas consequências; e tantos outros que contribuem para pesquisas que primam pelo entendimento de vários aspectos da formação de professores. A riqueza dos relatos revela um universo muito variado que interessa a quem forma professores e também deveria interessar aos que fazem as políticas educacionais de nosso país.

Para que as narrativas tenham de fato validade no campo de estudos da formação de professores é preciso atentar principalmente a dois fatores que as compõem: a experiência e a verbalização, considerando que o tipo de tratamento que lhes é dado pode alterar completamente o resultado das pesquisas.

A experiência das narrativas de formação vem sendo utilizada como proposta de formação de professores há anos, por implicar em uma transformação do sujeito aprendiz (DEMARTINI, 2008). Este poder de alterar a formação do sujeito advém da profunda reflexão necessária à escrita da narrativa, que acaba por colocar o narrador em "[...] um novo patamar de formação e autoformação" (VARANI; FERREIRA; PRADO, 2007, p. 10).

Apesar da crescente valorização das narrativas, Passegui (2011) nos mostra a necessidade de se ampliar a investigação sobre o real valor do narrar a própria vida no âmbito da formação dos sujeitos:

No Brasil, as pesquisas educacionais com fontes autobiográficas têm se voltado mais para as questões identitárias, notadamente, na formação docente. Ainda são raras aquelas que investigam a ressignificação da experiência no ato de narrar a própria vida. (p. 148).

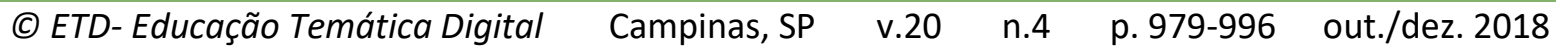


Ou seja, ainda é preciso que se pesquise mais sobre este assunto para que possamos dar um passo adiante ao que já é confirmado por tantos autores que escrevem sobre a importância da história de vida na formação de professores:

\begin{abstract}
De fato, as experiências formadoras vividas na família e na escola se dão antes mesmo que a pessoa tenha desenvolvido um aparelho cognitivo aprimorado para nomear e indicar o que ela detém dessas experiências. [...] A temporalidade estruturou, portanto, a memorização de experiências educativas marcantes para a construção do Eu profissional, e constituiu o meio privilegiado de chegar a isso. (TARDIF, 2014, p. 67).
\end{abstract}

Por esta ótica, viver implica em experiências contínuas, que geram aprendizagem, que formam o sujeito profissional. Esta formação não é compartimentada, mas, sim, globalizada, sendo o resultado de muitas influências por vezes imperceptíveis a nós. As narrativas contribuem para o refletir e possibilitam estabelecer conexões entre fatos e aprendizagens, gerando ressignificações que transformam o sujeito e geram novas aprendizagens.

\title{
7 ESCRITA NARRATIVA
}

A escrita narrativa em pesquisas é um gênero de escrita que transgride a forma academicamente tradicional, o que a torna praticamente não inserida em áreas chamadas 'duras'. Ou seja, ela é um modo relativamente novo de exposição dos resultados de pesquisa, normalmente usado em áreas sociais. A escrita narrativa quebra principalmente a tão apregoada regra da impessoalidade, que prima por considerar possível garantir a isenção do olhar do pesquisador. Ao contrário, o modo narrativo de escrita oferece liberdade ao pesquisador para expor seu olhar, seus sentimentos, suas percepções, sem, no entanto, perder de vista o que o embasa teoricamente. Em Clandinin e Connelly (2011) encontramos a defesa a este tipo de escrita. A pesquisa narrativa por eles explorada, pressupõe a escrita narrativa. Tal ação considera o quanto as diferentes formas de escrita se completam, produzindo um resultado textual que expressa o pesquisador e o pesquisado, sendo, ao nosso ver, uma escrita mais envolvente e complexa, cheia de ricas subjetividades e valorização de aspectos humanos com os quais nos identificamos mais facilmente, como ocorre com as próprias narrativas.

\footnotetext{
Trabalhando com os três tipos de texto de Chatman, todos os tipos argumentativos descritivos e narrativos - estão presentes. [...] Não podemos chamar um texto de pesquisa narrativa, se ele deixar de fora a descrição e a narrativa e usar somente argumentos. Nem podemos chamar um texto de narrativa se ele é uma narrativa pura sem descrição e argumento. (CLANDININ; CONNELLY, 2011, p. 203-204).
}

As pesquisas escritas narrativamente, assim como as narrativas em si, possuem muitas qualidades, mas, no entanto, não apresentam, necessariamente, verdades, pois são

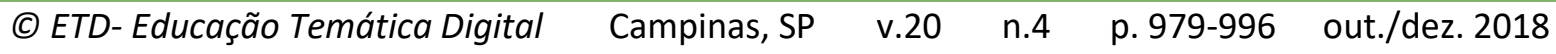


a produção de alguém que inevitavelmente transforma, de alguma forma, o objeto de pesquisa.

Quando uma pessoa relata os fatos vividos por ela mesma, percebe-se que reconstrói a trajetória percorrida dando-Ihe novos significados. Assim, a narrativa não é a verdade literal dos fatos mas, antes, é a representação que deles faz o sujeito e, dessa forma, pode ser transformadora da própria realidade. (CUNHA, 1997, on-line).

Portanto, há que se compreender que a escrita narrativa traz a visão de seu autor de modo mais explícito do que a escrita impessoal. Dizemos: 'mais explícito', porque nenhuma escrita é isenta de valores. Para Bakhtin (1992) todo discurso é ideológico. As escolhas que são feitas para a escrita de qualquer texto, implicam, necessariamente, em seleções que partem do autor e sua forma de compreensão de mundo e do assunto tratado. Sendo assim, não há, mesmo na escrita formalmente acadêmica a absoluta 'isenção de opinião'.

\section{SÍNTESE REFLEXIVA}

Acreditando no valor das histórias de vida e das experiências, aliadas às vozes das pesquisas, ao aprofundar-nos sobre o tema narrativas, várias questões surgiram e muitas inspirações também. As narrativas se mostram um universo de possibilidades que lida com elementos altamente educativos, como: reflexão, memória, subjetividade, análise, verbalização oral ou escrita, diálogo e integração. Escrever narrativamente e/ou utilizar narrativas em pesquisa ou como prática de formação são ações fecundas à área da Pedagogia.

Mas há aspectos que ainda merecem estudos mais aprofundados, especialmente os que dizem respeito às questões éticas do uso das narrativas. Cada envolvido nas pesquisas deve ter garantias do uso devido de suas narrativas, sejam elas, orais ou escritas, tanto no que diz respeito ao anonimato quanto ao texto que será divulgado. De maneira fundamental, a pesquisa que envolve narrativas tem que resguardar essa preocupação.

Cabe destacar que mesmo utilizando-se de todos os recursos para que a pesquisa busque retratar a realidade com a maior transparência possível, como em qualquer outra forma de apresentar uma pesquisa, apenas é possível descrever o que aquele pesquisador considera como verdade, a partir do lugar que ocupa, de suas vivências. Assim, o que ocorre com a pesquisa narrativa, não é diferente do que acontece em qualquer outra pesquisa: apresenta uma maneira, peculiar, de analisar e apresentar dados produzidos.

Portanto, em nossa análise demos destaque às subjetividades, dos participantes e dos pesquisadores, como sendo extremamente relevantes aos resultados das pesquisas. Para isso nos guiamos por autores aqui destacados, como Clandinin e Connelly, Souza, Passegui, Prado e outros que nos ensinam que o modo de inquirição narrativa deve ser

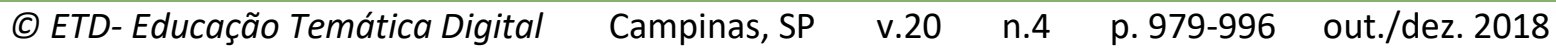


atenta às entrelinhas do que é exposto pelos participantes, defendendo o quanto isso é enriquecedor para as ciências, já que trazem revelações somente. Este nível de acesso às subjetividades é possível a modos de inquirição que permitem ampliação da voz dos participantes e de suas 'verdades' em consonância à sensibilidade dos pesquisadores em considerá-las.

Por fim, enfatizamos o quanto foi importante a estas pesquisadoras a categorização das narrativas. Sem a organização aqui apresentada a investigação que gerou este artigo, feita a partir da análise de 16 obras acadêmicas, não teria sido tão potente como resultado de pesquisa, já que o entendimento do modus operandi sobre as pesquisas narrativas foi fundamental para a análise das teses e dissertações em questão para nossa inquirição. Compreender e categorizar as diversas formas de uso das narrativas surgiu como uma necessidade para a nossa pesquisa e resultou em um instrumento sistematizado possível a outros pesquisadores e demais interessados em conhecer e utilizar as narrativas em pesquisa e ou formação.

\section{REFERÊNCIAS}

ALVES-MAZZOTTI, Alda Judith; GEWANDSZNAJDER, Fernando. 0 método nas ciências naturais e sociais: pesquisa quantitativa e qualitativa. São Paulo: Pioneira, 2000.

BAKHTIN, Mikhail. Marxismo e filosofia da linguagem. São Paulo: HUCITEC, 1992.

BARBISAN, Carla. Narrativas: usos e contribuições às pesquisas sobre formação inicial de pedagogos. 2017. 200 f. Dissertação (Mestrado em Educação) - Pontifícia Universidade Católica de Campinas, Centro de Ciências Humanas e Sociais Aplicadas, Campinas, SP, 2017.

BRITO, Angela Maria. (Org.). Memórias de formação: registros de percursos em diferentes contextos. Campo Grande, MS: UFMS, 2007.

CLANDININ, D. Jean, CONNELLY, F. Michael. Pesquisa narrativa: expectativas e histórias na pesquisa qualitativa. Uberlândia, MG: EDUFU, 2011.

CHIZZOTI, Antonio. Pesquisa qualitativa em ciências humanas e sociais. 4. ed. Petrópolis, RJ: Vozes, 2011.

CUNHA, Maria Isabel. Conta-me agora! : as narrativas como alternativas pedagógicas na pesquisa e no ensino. Revista da Faculdade de Educação, São Paulo, v. 23, n. 1-2, jan./dec. 1997. Disponível em: http://www.scielo.br/scielo.php?script=sci arttext\&pid=S010225551997000100010. Acesso em: 01 março 2017.

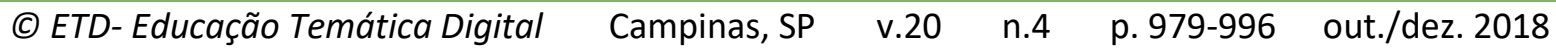


DERMARTINI, Zeila de Brito Fabri. Das histórias de vida às histórias de formação. In: SOUZA, Elizeu Clementino de; MIGNOT, Ana Chrystina Venâncio (Org.); Dirceu Castilho Pacheco et al. Histórias de vida e formação de professores. Rio de Janeiro: Quartet: FAPERJ, 2008.

DEWEY, John. Experiência e educação: tradução de Anísio Teixeira. 2. ed. São Paulo, Ed. Nacional, 1976.

FREITAS, Liliane Miranda, GHEDIN, Luiz Evandro. Narrativas de formação: origens, significados e usos na pesquisa-formação de professores. Revista Contemporânea de Educação, v.10, n.19, jan./jun. de 2015. Disponível em:

https://webcache.googleusercontent.com/search?q=cache:svy45H3mHmYJ:https://revistas. ufri.br/index.php/rce/article/view/1929+\&cd=1\&hl=pt-BR\&ct=clnk\&gl=br . Acesso em: 01 out. 2016.

FURLANETTO, Ecleide Cunico. Matrizes Pedagógicas e Formação Docente. Actas do X Congresso Internacional Galego-Português de PsicoPedagogia. Braga: Universidade do Minho, 2009. ISBN- 978-972-8746-71-1. Disponível em:

http://www.educacion.udc.es/grupos/gipdae/documentos/congreso/xcongreso/pdfs/t3/t3c 78.pdf . Acesso em: 26 nov. 2016.

GARCIA, Marcelo Carlos. A formação de professores: novas perspectivas baseadas na investigação sobre o pensamento do professor. In: NÓVOA, António (Org.). Os professores e sua formação. Lisboa, Portugal: Dom Quixote,1992.

JOSSO, M. C. Da formação do sujeito... ao sujeito da formação. In: NÓVOA, A; FINGER, M (Org.). $O$ método (auto)biográfico e a formação. Lisboa: Departamento de Recursos Humanos/Ministério da Saúde. 1988.

LARROSA, J. Notas sobre a experiência e o saber de experiência. Revista Brasileira de Educação, n. 19. jan./fev./mar./abr. 2002. Disponível em:

http://www.scielo.br/pdf/rbedu/n19/n19a02.pdf. Acesso em: 03 jun. 2016.

LARROSA, J. Experiência em educação. Revista Reflexão e Ação, Santa Cruz do Sul, v. 19, n. 2, p. 04-27, jul./dez. 2011. Disponível em:

https://online.unisc.br/seer/index.php/reflex/article/view/2444/1898 Acesso em: 08 ago. 2016.

MEGID, Maria Auxiliadora Bueno Andrade. Formação inicial de professoras mediada pela escrita e pela análise de narrativas sobre operações numéricas. 2009, 284 p. Tese (Doutorado em Educação Matemática). Faculdade de Educação, Universidade Estadual de Campinas, 2009.

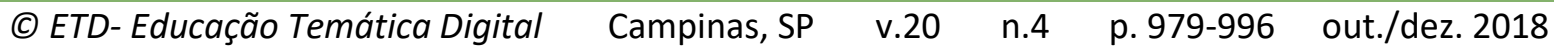


NOGUEIRA, Eliane Greice Davanço et al. A escrita de memoriais a favor da pesquisa e da formação. In: SOUZA, Elizeu Clementino de; MIGNOT, Ana Chrystina Venâncio (Org.); Dirceu Castilho Pacheco [et al]. Histórias de vida e formação de professores. Rio de Janeiro: Quartet: FAPERJ, 2008.

PASSEGUI, Maria da Conceição. A experiência em formação. Educação, Porto Alegre, v. 34, n. 2, p. 147-156, maio/ago. 2011. Disponível em:

http://revistaseletronicas.pucrs.br/ojs/index.php/faced/article/view/8697. Acesso em: 13 nov. 2016.

PRADO, Guilherme do Val Toledo; SOLIGO, Rosaura (Org.). Porque escrever é fazer história. Campinas, SP: Graf. FE, 2005.

SOUZA, Elizeu Clementino; OLIVEIRA, Rita de Cássia Magalhães. Entre fios e teias de formação: escolarização, profissão e trabalho docente em escola rural. In: VICENTINI, Paula Perin; SOUZA, Elizeu Clementino de; PASSEGUI, Maria da Conceição (Org.). Pesquisa (auto)biográfica: questões de ensino e formação. Curitiba, PR: CVR, 2013.

SOUZA, Elizeu Clementino de; PASSEGUI, Maria da Conceição. Pesquisa (auto)biográfica: questões de ensino e formação. Curitiba, PR: CRV, 2013.

SOUZA, Elizeu Clementino de; MIGNOT, Ana Chrystina Venâncio (Org.); Dirceu Castilho Pacheco [et al]. Histórias de vida e formação de professores. Rio de Janeiro, RJ: Quartet: FAPERJ, 2008

TARDIF, Maurice. Saberes docentes e formação profissional. 16. ed. Petrópolis, RJ: Vozes, 2014.

VARANI, Adriana; FERREIRA, Cláudia Roberta; PRADO, Guilherme do Val Toledo Prado, (Org.). Narrativas docentes: trajetória de trabalhos pedagógicos. Campinas, SP: Mercado de letras, 2007.

VICENTINI, Paula Perin; SOUZA, Elizeu Clementino de; PASSEGUI, Maria da Conceição (Org.). Pesquisa (auto)biográfica: questões de ensino e formação. Curitiba, PR: CRV, 2013.

* Revisão gramatical do texto sob responsabilidade de:

Mariana Azank Veltri - E-mail: mariveltri@yahoo.com.br

(C) ETD- Educação Temática Digital Campinas, SP $\quad$ v.20 $\quad$ n.4 $\quad$ p.979-996 out./dez. 2018

